\title{
DETERMINAN BUDAYA ORGANISASI, MOTIVASI DAN DISIPLIN KERJA DALAM MENINGKATKAN KINERJA GURU SEKOLAH ISLAM TERPADU
}

Uus MD Fadli, Dini Dewanti, Asep Jamaludin uus.fadli@ubpkarawang.ac.id asepjamaludin@ubpkarawang.ac.id

\begin{abstract}
ABSTRAK
Penelitian ini bertujuan untuk mendeskripsikan Budaya Organisasi, Motivasi, Disiplin dan Kinerja Guru serta mengetahui hubungan diantara keempat variable tersebut. Metoda penelitian menggunakan deskriptif verifikatif, explanatory survey. Sampel dari penelitian ini adalah guru di Sekolah Islam Terpadu Al-Irsyad Al-Islamiyyah Karawang. Teknik penarikan sampel dengan menggunakan stratified random sampling, pada strata unit lembaga TK, SD dan SMP, dengan jumlah sampel sebanyak 94 orang guru.

Hasil penelitian menunjukkan bahwa Guru di Lembaga terebut memiliki Budaya Organisasi, Motivasi, Disiplin dan Kinerja yang tinggi yang mendukung berjalannya pendidikan yang baik.Budaya organisasi berpengaruh pada taraf yang sedang terhadap motivasi kerja, dan berpengaruh kuat terhadap disiplin kerja. Terdapat korelasi yang rendah antara motivasi dan disiplin kerja. Motivasi guru berperan rendah terhadap kinerja guru, tetapi displin kerja berpengaruh kuat terhadap kinerja guru. Secara simultan Motivasi dan disiplin berpengaruh kuat terhadap kinerja guru.
\end{abstract}

Kata Kunci : $\quad$ Budaya Organisasi, Motivasi, Disiplin, Kinerja.

\section{PENDAHULUAN}

Sekolah Islam Terpadu Al-Irsyad Al-Islamiyyah Karawang telah mempertahankan pelayanan kualitas pendidikannya dengan memperoleh outcome dari layanan pendidikan, yaitu siswa yang telah lulus dari sekolah tersebutdengan menunjukkan peningkatan hasil yang signifikan secara kualitas dan kuantitas.Peningkatan kualitas dan jumlah siswa dari tahun ke tahun tersebut haruslah diimbangi dengan peningkatan kualitas serta jumlah tenaga pendidik.Menurut Raymond A. Noe, John R.H., Barry G dan Pattrick M.W. (2011:35) banyak yang dapat dipetik dari survey kepuasan karyawan, oleh karena itu, sangat mengejutkan halnya bahwa banyak perusahaan yang secara teratur melakukan survey kepuasan konsumen ternyata justru gagal menunjukkan kepedulian yang sama dalam hal kepuasan karyawan. Retensi merupakan masalah yang melibatkan pelanggan dan karyawan, dan kedua tipe retensi ini sangat berkaitan.

Biro HRD sekolah telah berupaya melakukan motivasi guru dengan memenuhi seluruh aspek fasilitas ketika guru tersebut melakukan pekerjaan, memberikan fasilitas terbaik kepada guru untuk pemenuhan kebutuhan guru. Sondang P. Siagian (2014:295297) memaparkan mengenai Kinerja dalam berbagai penelitian yang membuktikan bahwa 
seorang pekerja (guru) yang "puas" tidak dengan sendirinya merupakan pekerja yang berprestasi tinggi, melainkan sering hanya berprestasi "biasa-biasa saja".Jika demikian halnya, dapat pula dikatakan bahwa kepuasan kerja tidak selalu menjadi faktor motivasional kuat untuk berprestasi. Terlepas dari faktor-faktor apa yang dijadikan sebagai alat pengukur kepuasan kerja, tetap penting untuk mengusahakan agar terdapat korelasi positif antara kepuasan dengan kinerja. Artinya, menjadikan kepuasan untuk memacu kinerja yang lebih baik meskipun disadari bahwa hal itu tidak mudah.

Yayasan atau LPP (Lajnah/ Lembaga Pendidikan dan Pengajaran) telah melakukan upaya untuk memfasilitasi para gurunya dalam meningkatkan Kinerja, yaitu dengan menggunakan sistem manajemen kinerja (Performance Management System) untuk membantu guru dalam meningkatkan kinerja, bimbingan karir dan evaluasi kerja yang dilakukan minimal setahun sekali (Peraturan Kepegawaian LPP Al-Irsyad Al-Islamiyyah Karawang, Pasal 12 butir 1).

Tenaga didik sebagai guru di yayasan tersebut hakikatnya bukanlah dianggap sebagai biaya atau beban, melainkan modal atau investasi yang dapat dikembangkan sehingga mempermudah organisasi mencapai tujuannya.Sehingga, guru menjadi tenaga didik yang profesional serta merupakan salah satu investasi organisasi yang harus dikembangkan.Seperti dikutip dari Undang Undang Nomor 14 Tahun 2005, Bab III mengenai Prinsip Profesionalitas Guru dan Dosen, Pasal 7 (f) memperoleh penghasilan yang ditentukan sesuai dengan Kinerja, serta Pasal 7 (g) memiliki kesempatan untuk mengembangkan keprofesionalan secara berkelanjutan dengan belajar sepanjang hayat.

Menurut Raymond A. Noe, John R.H., Barry G dan Pattrick M.W. (2011:17-18) bahwa penarikan diri dari pekerjaan (job withdrawal) merupakan serangkaiaan perilaku yang diambil oleh individu yang tidak puas untuk menghindari situasi kerja. Menurut Sinambela (2012:255) kepuasan kerja dan disiplinguru berhubungan erat dengan kinerja guru,kepuasan kerja dapat menekan tingkat keluarnya guru dan banyaknya respon ketidakpuasan. Selanjutnya, Sinambela (2012:237) memaparkan bahwa terdapat hubungan yang signifikan antara variabel kinerja dan disiplin kerja.

Kenneth N. Wexley dan Gary A. Yuki (2015:117) memaparkan kondisi-kondisi yang membatasi insentif upah atau gaji. Menurutnya terdapat beberapa persyaratan agar program insentif upah atau gaji layak diterapkan sebagai cara meningkatkan kepuasan atau modifikasi perilaku pekerja, salah satu dari antaranya adalah terdapat nsentif upah atau gaji dapat dijadikan ikatan atas pelaksanaan kerja atau perilaku yang diinginkan dengan cara yang dimengerti para pekerja. 
Perubahan struktur organisasi pada yayasan atau Lajnah Pendidikan dan Pengajaran Al-Irsyad Al-Islamiyyah Karawang dikarenakan proses untuk penyesuaian menuju perbaikan mutu mengikuti bentuk organisasi dengan Al-Irsyad Al-Islamiyyah cabang lainnya.Menurut Tubagus Achmad Darojat (2015:238) budaya organisasi merupakan hal dasar yang harus dimiliki sebuah perusahaan untuk dapat bertahan, terus maju dan berkembang, serta memenangkan persaingan dengan organisasi lainnya. Selanjutnya Ben Fletcher dan Fiona Joner dalam Tubagus Achmad Darojat (2015:239) menyatakan bahwa budaya organisasi juga mempunyai dampak negatif di dalam suatu organisasi harus diperhatikan sebab-sebab dari problem berasal, serta hasil akhir (outcome), yang menyangkut kinerja, komitmen organisasi, dan ketidakpuasan kerja.

\section{Budaya Organisasi}

Menurut Laurie J. Mullins dalam Tubagus Achmad Darojat (2015:243) Budaya Organisasi merupakan kumpulan tradisi, nilai-nilai, keyakinan dan sikap-sikap yang membentuk konteks yang dominan bagi segala sesuatu yang kita lakukan di dalam suatu organisasi.Peter F. Drucker dalam Moh.Pabundu Tika (2014:4) berpendapat bahwa budaya organisasi adalah pokok penyelesaian masalah-masalah eksternal dan internal yang pelaksanaannya dilakukan secara konsisten oleh suatu kelompok yang tepat memahami, memikirkan dan merasakan terkait masalah-masalah terkait seperti diatas.Menurut Tubagus Achmad Darojat (2015:244) Budaya Organisasi merupakan sekumpulan nilai-nilai, keyakinan, asumsi-asumsi yang dibentuk oleh para pendiri organisasi tersebut dan diteruskan kepada bawahannya terus menerus sehingga tanpa disadari menjadi tradisi dan diterima oleh anggota organisasi yang menjadi dasar bertindak atau tidak untuk memecahkan masalah, dan mencapai tujuan organisasi.

Menurut Stephen P. Robbins dalam Djokosantoso Moeljono (2015:11-15) terdapat 7 Karakteristik Budaya Organisasi dimana tiap karakteristik itu bergerak pada suatu kontinum dari rendah ke tinggi. Adapun dimensi tersebut adalah :Inovasi dan keberanian mengambil resiko (innovation and risk tasking), Perhatian terhadap detail(Inovation and risk taking), Berorientasi kepada hasil (Outcome orientation), Berorientasi kepada manusia (People orientation), Berorientasi Tim (Tim orientation), Agresif (Aggressiveness), Stabil(Stability).

\section{Motivasi Kerja}

Menurut Berelson dan Steiner dalam Tubagus Achmad Darojat (2015:187) berpendapat "A Motive is an inner state that energizes, activitiesor move, and that directs or channels behavior to ward goals."Artinya :Motivasi adalah daya dorong yang datang dari dalam diri seseorang yang mengarahkan perilaku untuk mencapai suatu 
tujuan.Suparno Eko Widodo (2015:187) mendefinisikan bahwa motivasi adalah kekuatan yang ada dalam seseorang, yang mendorong perilakunya untuk melakukan tindakan.Wukir (2013:115) berpendapat bahwa kata motivasi berasal dari bahasa latin "movere" yang berarti to move (untuk bergerak). Motivasi merupakan seperangkat alasan dalam melakukan tindakan tertentu. Motivasi dapat didefinisikan sebagai proses yang menjelaskan intensitas, arah dan ketekunan seseorang dalam berusaha mencapai tujuannya.Veithzal Rivai dan Ella Jauvani Sagala (2010:837) berpendapat bahwa motivasi adalah serangkaian sikap dan nilai yang mempengaruhi individu untuk mencapai hal yang spesifik sesuai dengan tujuan individu. Anwar Prabu Mangkunegara (2013:93) menyatakan bahwa motivasi adalah kondisi yang menggerakkan guruagar mampu mencapai tujuan dari motifnya.

David McClelland dalam Veithzal Rivai dan Ella Jauvani Sagala (2010:840-841) memaparkan Teori Kebutuhan yang mempengaruhi motivasi, yaitu Kebutuhan untuk mencapai kesuksesan (Need For Achievement), Kebutuhan untuk berafiliasi (Need For Affiliation), Kebutuhan dalam otoritas kerja (Need For Power).

\section{Disiplin}

Menurut Aritonang dalam Mohammad Arifin dan Barnawi (2014:110) bahwa Disiplin pada hakikatnya adalah kemampuan untuk mengendalikan diri dalam bentuk tidak melakukan sesuatu tindakan yang tidak sesuai atau bertentangan dengan sesuatu yang telah ditetapkan.Juga, melakukan sesuatu yang mendukung dan melindungi sesuatu yang telah ditetapkan.Sedangkan Disiplin Kerja adalah persepsi guru terhadap sikap pribadi guru dalam bekerja di sekolah tanpa ada pelanggaran-pelanggaran yang merugikan dirinya, orang lain, atau lingkungannya.Menurut Keith Davis dalam AA Anwar Mangkunegara (2013:129) mengemukakan bahwaDiscpiline is management action to enforce organization standards.Artinya, Disiplin adalah pelaksanaan menejemen untuk memperteguh pedoman-pedoman organisasi.Veithzal Rivai (2010:825) menjelaskan bahwa Disiplin kerja adalah suatu alat yang digunakan para manajer untuk berkomunikasi dengan karyawan agar mereka bersedia untuk mengubah suatu perilaku serta sebagai suatu upaya untuk meningkatkan kesadaran dan kesediaan seseorang mentaati semua peraturan perusahaan dan norma-norma sosial yang berlaku.

Aritonang dalam Mohammad Arifin dan Barnawi (2014:124) memaparkan lingkup disiplin kerja guru mencakup empat dimensi disiplin yang harus diperhatikan, yaitu :Disiplin terhadap tugas kedinasan, Disiplin terhadap waktu, Disiplin terhadap suasana kerja, Disiplin di dalam melayani masyarakat, Disiplin terhadap sikap dan tingkah laku.

\section{Kinerja}


Menurut A.A. Anwar Prabu Mangkunegara (2013:67) Pengertian Kinerja adalah hasil kerja secara kualitas dan kuantitas yang dicapai oleh seorang Guru dalam melaksanakan tugasnya sesuai dengan tanggung jawab yang diberikan kepadanya.Menurut Suparno Eko Widodo (2015:131) Kinerja individu adalah bagian hasil dari kerja Guru baik dari segi kualitas maupun kuantitas berdasarkan standar kerja yang telah ditentukan, sedangkan kinerja organisasi adalah gabungan dari kinerja individu dan kelompok.Menurut Veithzal Rivai (2010:548) Kinerja adalah fungsi motivasi dan kemampuan, yang ditampilkan setiap orang sebagai hasil kerja sesuai dengan perananya dalam perusahaan untuk mencapai tujuan.Menurut Tubagus Achmad Darojat (2015:105) Kinerja adalah suatu tindakan atau kegiatan yang ditampilkan oleh seseorang dalam melaksanakan aktivitas tertentu yang menjadi tugasnya.Menurut Barry M. Staw dalam Taliziduhu Ndraha (2012:140) Kinerja individu (Individual Performance) adalah dorongan (drives), kebutuhan (needs) dan dampak (outcomes) yang diharapkan oleh subjek (pelaku).

Dalam Pedoman Pelaksanaan Penilaian Kinerja Guru dipaparkan mengenai dimensi kinerja guru oleh Direktorat Jenderal PMPTK (Peningkatan Mutu Pendidik dan Tenaga Kependidikan) (2010:4-6) yang mengacu pada Undang-Undang Nomor 14 Tahun 2005 Tentang Guru dan Dosen Pasal 35, sebagai berikut : Perencanaan Pembelajaran, Pelaksanaan Pembelajaran dan Penilaian Pembelajaran.

\section{METODE PENELITIAN}

Penelitian digunakan dengan menggunakan metoda deskriptif dan verifikatif, yaitu : mengumpulkan, menyajikan, menganalisis dan melakukan pengujian hipotesis, serta membuat Simpulan dan Saran. Desain penelitian yang digunakan adalah explanatory survey. Sampel dari penelitian ini adalah guru di Sekolah Islam Terpadu AlIrsyad Al-Islamiyyah Karawang.

Teknik penarikan sampel dengan menggunakan stratified random sampling, yaitu teknik pengambilan sampel dengan mengambil dari unit lembaga TK, SD dan SMP. Sampel yang diambil dari penelitian ini sebanyak 94 orang guru, diambil dari jumlah populasi guru sebanyak 101 orang.

Dalam penelitian ini yang menjadi variabel dependen dan independen, dapat digambarkan secara jelas melalui bagan di bawah ini :

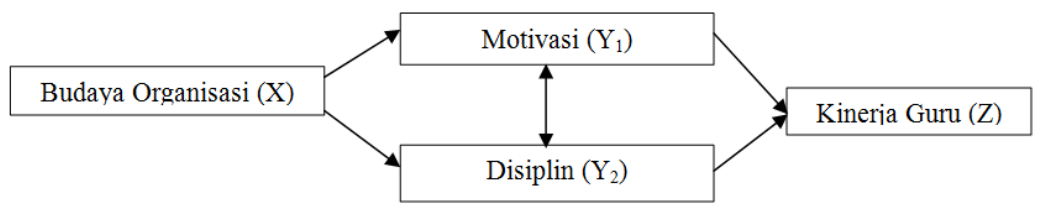

Gambar 1 : Model Hubungan Antar Variabel Yang Diteliti 
Hipotesis

1. Terdapat pengaruh parsial budaya organisasi terhadap motivasi.

2. Terdapat pengaruh parsial budaya organisasi terhadap disiplin.

3. Terdapat korelasi motivasi dengan disiplin.

4. Terdapat pengaruh simultan motivasi dan disiplin terhadap kinerja guru.

\section{HASIL PENELITIAN}

\section{Uji Validitas, Reliabilitasdan Normalitas}

Hasil analisis validitas seluruh item pertanyaan pada seluruh variabel dinyatakan valid karena nilai korelasi > dari nilai kritis, yaitu 0,3. Hasil analisis Reliabilitas didapatkan seluruh item pertanyaan pada seluruh variabel yang telah diuji adalah reliabel atau baik untuk digunakan dalam penelitian ini, karena nilai alpha seluruh item pada seluruh variabel masuk ke dalam kriteria baikdiatas 0,80 .

Berdasarkan uji normalitas data dengan menggunakan Kolmogorov-Smirnov Test, maka didapatkan hasil yaitu untuk variabel budaya organisasi sebesar 0,796 $(<1,96)$, variabel motivasi sebesar 1,411 $(<1,96)$, variabel motivasi sebesar 1,004 $(<1,96)$, dan untuk variabel kinerja sebesar 1,439 $(<1,96)$, serta angka signifikansi (sig) $>0,05$ maka dapat disimpulkan bahwa seluruh data tersebut berdistribusi normal.

\section{Analisis Deskriptif}

Secara deskriptif Budaya organisasi, fenomena yang paling banyak muncul atau modus yaitu pada nilai skor 349. Artinya budaya organisasi di Sekolah SDIT Al Irsyad masuk ke dalam kriteria tinggi.

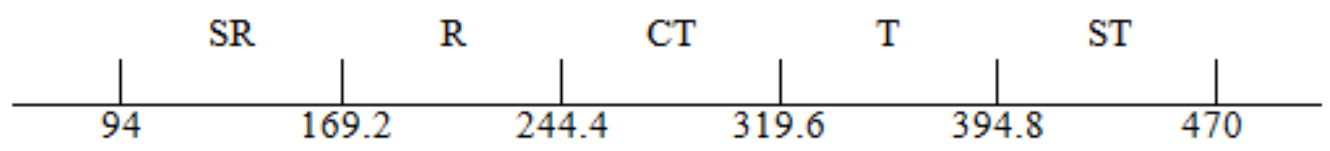

Gambar 2 : Skala Pengukuran Penelitian

Skor terendah adalah butir pertanyaan nomor 15, yaitu tingkat kenyamanan setiap guru dalam bekerja di sekolah ini pada kondisi seperti apapun. Analisis deskirptif untuk motivasi guru menunjukkan fenomena yang paling banyak muncul atau modus yaitu pada nilai skor 332. Motivasi masuk ke dalam kriteria tinggi. Skor terendah terletak pada butir pertanyaan nomor 11, yaitu kepuasan kerja setiap guru walau pekerjaan terasa berat (tidak terbebani dengan pekerjaan). Analisis deskirptif untuk variabel disiplin bahwa fenomena yang paling banyak muncul atau modus yaitu pada nilai 359. Maka, disiplin masuk ke dalam kriteria tinggi. Skor terendah ada pada butir pertanyaan nomor 9, yaitu tingkat keseimbangan antara hak dan kewajiban yang dirasakan oleh setiap guru. Analisis 
deskirptif untuk variabel kinerja bahwa fenomena yang paling banyak muncul atau modus yaitu pada nilai 374. Maka,kinerja masuk ke dalam kriteria tinggi. Skor nilai terendah adalah butir pertanyaan point nomor 14, yaitu tingkat pemanfaatan berbagai hasil penilaian untuk memberikan umpan balik bagi peserta didik tentang kemajuan belajarnya dan bahan penyusunan rancangan pembelajaran selanjutnya oleh setiap guru.

\section{Pengaruh Budaya Organisasi $(\mathbf{X})$ terhadap Motivasi $\left(\mathbf{Y}_{1}\right)$}

Dari hasil pengolahan data statistik menggunakan alat bantu SPSS 16.0 untuk mengukur pengaruh Budaya Organisasi terhadap Motivasi, maka didapatkan hasil sebagaimana ditampilkan pada table 1 di bawah ini.

\section{Tabel 1 : Coefficients ${ }^{a}$ Budaya Organisasi-Motivasi}

\begin{tabular}{|c|c|c|c|c|c|c|}
\hline & \multirow{2}{*}{ Model } & \multicolumn{2}{|c|}{$\begin{array}{c}\text { Unstandardized } \\
\text { Coefficients }\end{array}$} & \multirow{2}{*}{\begin{tabular}{|c|}
$\begin{array}{c}\text { Standardized } \\
\text { Coefficients }\end{array}$ \\
Beta \\
\end{tabular}} & \multirow[t]{2}{*}{$\mathrm{T}$} & \multirow{2}{*}{ Sig. } \\
\hline & & B & Std. Error & & & \\
\hline \multirow[t]{2}{*}{1} & (Constant) & 2.169 & .321 & & 6.758 & .000 \\
\hline & BudayaOrganisasi & .359 & .085 & .403 & 4.221 & .000 \\
\hline
\end{tabular}

a. Dependent Variable: Motivasi

Pengaruh parsial dari Budaya Organisasi $(\mathrm{X})$ terhadap Motivasi Kerja ( $\left.\mathrm{Y}_{1}\right)$ memiliki koefisien jalur sebesar 0,403 dan sangat signifikan, sehingga persamaan jalur dari variabel yang diteliti adalah : $\mathrm{Y}_{1}=0,403 \mathrm{X}$

$$
\text { Keterangan: } \begin{aligned}
\mathrm{Y}_{1} & =\text { Motivasi Kerja } \\
\mathrm{X} & =\text { Budaya Organisasi }
\end{aligned}
$$

Sumbangan Budaya Organisasi $(\mathrm{X})$ dalam meningkatkan Motivasi Kerja Guru $\left(\mathrm{Y}_{1}\right)$ dijelaskan dengan analisis koefisien determinasi sebesar $\mathrm{KD}=0.403^{2} \times 100 \%=16,24 \%$

\section{Pengaruh Budaya Organisasi $(\mathbf{X})$ terhadap Disiplin $\left(\mathbf{Y}_{2}\right)$}

Pengaruh Budaya Organisasi terhadap Disiplin ditampilkan pada table 2.

Tabel 2 : Coefficients ${ }^{a}$ Budaya Organisasi-Disiplin

\begin{tabular}{|l|r|r|r|r|r|}
\hline \multirow{2}{*}{ Model } & \multicolumn{2}{|c|}{$\begin{array}{c}\text { Unstandardized } \\
\text { Coefficients }\end{array}$} & $\begin{array}{c}\text { Standardized } \\
\text { Coefficients }\end{array}$ & \multirow{2}{*}{$\mathrm{T}$} & \multirow{2}{*}{ Sig. } \\
\cline { 2 - 5 } & \multicolumn{1}{|c|}{$\mathrm{B}$} & Std. Error & \multicolumn{1}{c|}{ Beta } & & \\
\hline 1 (Constant) & 1.656 & .249 & & 6.646 & .000 \\
BudayaOrganisasi & .588 & .066 & .680 & 8.891 & .000 \\
\hline
\end{tabular}

a. Dependent Variable: Disiplin

Pengaruh Budaya Organisasi (X) terhadap Disiplin $\left(\mathrm{Y}_{2}\right)$ pada Sekolah Islam Terpadu Al-Irsyad Al-Islamiyyah Karawang memiliki koefisien jalur sebesar 0,680 dan sangat signifikan, sehingga persamaan jalur variabel yang diteliti adalah : $\mathrm{Y}_{2}=0,680 \mathrm{X}$

Keterangan : $\mathrm{Y}_{2}=$ Disiplin dan $\mathrm{X}=$ Budaya Organisasi 
Kontribusi Budaya Organisasi $(\mathrm{X})$ terhadap Disiplin $\left(\mathrm{Y}_{2}\right)$ pada Sekolah Islam Terpadu Al-Irsyad Al-Islamiyyah Karawang dijelaskan dengan analisis koefisien determinasi KD $=0.680^{2} \times 100 \%=46,24 \%$

\section{Korelasi Motivasi $\left(\mathbf{Y}_{1}\right)$ dan Disiplin $\left(\mathbf{Y}_{2}\right)$}

Korelasi Motivasi dan Disiplin dijelaskan pada table 3 di bawah ini.

Tabel 3 : Correlations Motivasi dan Disimplin Kerja Guru

\begin{tabular}{|c|r|r|}
\hline & \multicolumn{1}{|c|}{ Motivasi } & \multicolumn{1}{|c|}{ Disipiln } \\
\hline Motivas Pearson & 1 & $.342^{* *}$ \\
Correlation & & .001 \\
Sig. (2-tailed) & 94 & 94 \\
$\mathrm{~N}$ & $.342^{* *}$ & 1 \\
\hline Disiplin Pearson & .001 & \\
Correlation & 94 & 94 \\
Sig. (2-tailed) & \\
$\mathrm{N}$ & \multicolumn{2}{|c|}{${ }^{*}$. Correlation is significant at the 0.01 level (2-tailed). }
\end{tabular}

Korelasi Motivasi $\left(\mathrm{Y}_{1}\right)$ dan Disiplin $\left(\mathrm{Y}_{2}\right)$ pada Sekolah Islam Terpadu Al-Irsyad Al-Islamiyyah Karawang sebesar 0,342 dan sangat signifikan.

\section{Pengaruh Motivasi $\left(\mathbf{Y}_{1}\right)$ dan Disiplin $\left(\mathbf{Y}_{2}\right)$ terhadap Kinerja $(Z)$}

Pengaruh Simultan dari Motivasi $\left(\mathrm{Y}_{1}\right)$ dan Disiplin $\left(\mathrm{Y}_{2}\right)$ terhadap Kinerja $(\mathrm{Z})$ pada Sekolah Islam Terpadu Al-Irsyad Al-Islamiyyah Karawang dalam penelitian ini dijelaskan melalui model dan hasil analisis pada tabel berikut.

Tabel 3 : Pengaruh Motivasi dan Disiplin terhadap Kinerja Guru

Coefficients $^{a}$

\begin{tabular}{|c|c|c|c|c|c|c|}
\hline & \multirow[t]{2}{*}{ Model } & \multicolumn{2}{|c|}{$\begin{array}{c}\text { Unstandardized } \\
\text { Coefficients }\end{array}$} & \multirow{2}{*}{$\begin{array}{c}\text { Standardized } \\
\text { Coefficients } \\
\text { Beta } \\
\end{array}$} & \multirow[t]{2}{*}{$\mathrm{T}$} & \multirow[t]{2}{*}{ Sig. } \\
\hline & & $\mathrm{B}$ & Std. Error & & & \\
\hline \multirow[t]{3}{*}{1} & (Constant) & -.468 & .255 & & -1.836 & .070 \\
\hline & Motivasi (Y1) & .046 & .036 & .100 & 1.296 & .198 \\
\hline & Disiplin (Y2) & .745 & .085 & .681 & 8.807 & .000 \\
\hline
\end{tabular}

a. Dependent Variable: Kinerja (Z)

\section{Pengaruh Parsial Motivasi $\left(\mathrm{Y}_{1}\right)$ terhadap Kinerja $(\mathrm{Z})$}

Pengaruh parsial dari Motivasi $\left(\mathrm{Y}_{1}\right)$ terhadap Kinerja $(\mathrm{Z})$ pada Sekolah Islam Terpadu Al-Irsyad Al-Islamiyyah Karawang memiliki koefisien jalur sebesar 0,100 (sangat lemah dan tidak signifikan). Persamaan jalur $\mathrm{Z}=0,1 \mathrm{Y}_{1}$

Keterangan : $\mathrm{Y}_{1}=$ Motivasi Kerja dan $\mathrm{Z}=$ Kinerja

Kontribnusi Motivasi Kerja ( $\left.\mathrm{Y}_{1}\right)$ terhadap Kinerja $(\mathrm{Z})$ pada Sekolah Islam Terpadu AlIrsyad Al-Islamiyyah Karawang sangat kecil (1\%) dan tidak sgnifikan. 


\section{Pengaruh Parsial Disiplin $\left(\mathbf{Y}_{2}\right)$ terhadap Kinerja $(\mathbf{Z})$}

Pengaruh parsial dari Disiplin $\left(\mathrm{Y}_{2}\right)$ terhadap Kinerja $(\mathrm{Z})$ pada Sekolah Islam Terpadu AlIrsyad Al-Islamiyyah Karawang memiliki koefisien jalur sebesar 0,681 (Kuat dan sangat signifikan). Ppersamaan jalur $\mathrm{Z}=0,681 \mathrm{Y}_{2}$ (Ket : $\mathrm{Y}_{2}=$ Disiplin dan $\mathrm{Z}=$ Kinerja Guru) Kontribusi Disiplin $\left(\mathrm{Y}_{2}\right)$ terhadap Kinerja $(\mathrm{Z})$ pada Sekolah Islam Terpadu Al-Irsyad AlIslamiyyah Karawang dijelaskan dengan koefisien determinasi sebesar sebesar 46,37\%.

\section{Pengaruh simultan Motivasi $\left(Y_{1}\right)$ dan Disiplin ( $\left.Y_{2}\right)$ terhadap Kinerja $(Z)$}

Pengaruh simultan dari Motivasi $\left(\mathrm{Y}_{1}\right)$ dan Disiplin $\left(\mathrm{Y}_{2}\right)$ terhadap Kinerja Guru $(\mathrm{Z})$ Sekolah Islam Terpadu Al-Irsyad Al-Islamiyyah Karawang digambarkan melalui model pada gambar 3 di bawah ini.

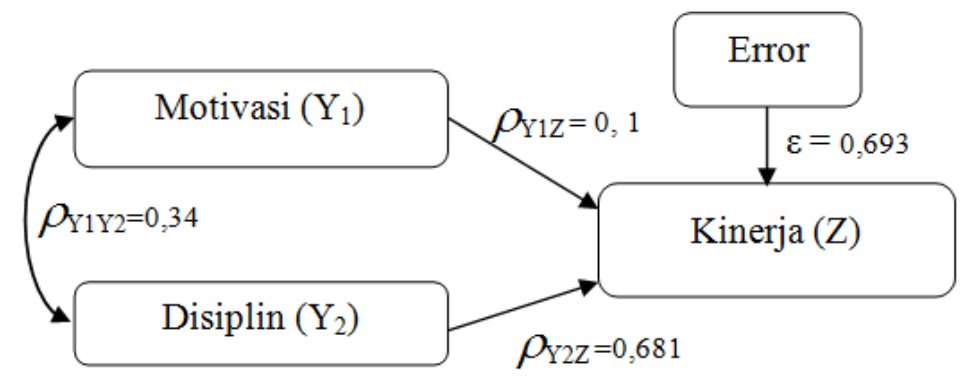

Gambar 3 : Pengaruh Simultan Motivasi dan Disiplin terhadap Kinerja Pada Sekolah Islam Terpadu Al-Irsyad Al-Islamiyyah Karawang

Tabel 4 : Pengaruh Simultan Motivasi ( $\left.\mathrm{Y}_{1}\right)$ dan Disiplin ( $\left.\mathrm{Y}_{2}\right)$ terhadap Kinerja $(\mathrm{Z})$

\begin{tabular}{|c|c|c|c|c|c|}
\hline Hubungan & $\begin{array}{c}\text { Koefisien } \\
\text { Jalur }\end{array}$ & Pengaruh Langsung & \multicolumn{2}{|c|}{ Pengaruh Tidak Langsung } & $\begin{array}{c}\text { Total } \\
\text { Pengaruh }\end{array}$ \\
\cline { 3 - 5 } $\begin{array}{c}\text { Pengaruh } \mathrm{Y}_{1} \\
\text { Terhadap Z }\end{array}$ & 0.1 & $(0.1)^{*}(0.1)=0.01$ & - & $\begin{array}{c}(0.1 * 0.342 \\
* 0.681)= \\
0.0233\end{array}$ & 0,0333 \\
\hline $\begin{array}{c}\text { Pengaruh } \mathrm{Y}_{2} \\
\text { Terhadap Z }\end{array}$ & 0.681 & $\begin{array}{c}(0.681)^{*}(0.681)= \\
0.463\end{array}$ & $\begin{array}{c}(0.1 * 0.342 * 0.6 \\
81)=0.0233\end{array}$ & - & 0.4863 \\
\hline \multicolumn{5}{|c|}{ Total Pengaruh Simultan } & 0,5196 \\
\hline \multicolumn{5}{|c|}{ Pengaruh Faktur lain } & $1-0,5196=0,4804=48,04 \%$ \\
\hline
\end{tabular}

\begin{tabular}{|l|r|r|r|r|r|}
\hline Model & \multicolumn{1}{|c|}{$\mathrm{R}$} & $\mathrm{R}$ Square & $\begin{array}{c}\text { Adjusted } R \\
\text { Square }\end{array}$ & $\begin{array}{c}\text { Std. Error of } \\
\text { the Estimate }\end{array}$ & $\begin{array}{c}\text { Durbin- } \\
\text { Watson }\end{array}$ \\
\hline 1 & $.721^{\mathrm{a}}$ & .520 & .509 & .39607 & 1.599 \\
\hline
\end{tabular}

a. Predictors: (Constant), Disiplin, Motivasi

b. Dependent Variable: Kinerja 
Persamaan Jalur Simultan :

$$
\mathrm{Z}=0.1 \mathrm{Y} 1+0.681 \mathrm{Y} 2+0.693
$$

$\mathrm{Z}=$ Kinerja Guru

Y1 = Motivasi

$\mathrm{Y} 2=$ Disiplin

$\varepsilon \quad=$ Error (koefisien jalur variabel lain) $=0,693$

Kontribusi Motivasi dan Disiplin terhadap Kinerja Guru adalah sebesar $52 \%$ dan terdapat faktor lain sebesar $48 \%$ (pembulatan) peran dari faktor lain yang tidak diteliti yang dapat meningkatkan Kinerja Guru pada Sekolah Islam Terpadu Al-Irsyad AlIslamiyyah Karawang.

\section{Diskusi}

Dari hasil penelititian ini hendaknya manajemen sebagai penyedia layanan pendidikan memberikan fasilitas layanan internal kepada guru agar setiap guru dapat nyaman dalam bekerja di sekolah ini pada kondisi seperti apapun. Diperlukan fasilitas kegiatan pelatihan untuk merangsang tingkat kesungguhan pekerjaan yang dilakukan agar menjadi guru berprestasi. Untuk memicu tingkat inovasi setiap guru,perlu memberikan reward atau penghargaan, agar guru dapat beraktualisasi diluar rutinitas untuk meningkatkan kemampuan siswa menjadi berprestasi.

Sebaiknya Yayasan menyediakan fasilitas kegiatan untuk merangsang tingkat persaingan antar guru agar menjadikan guru bekerja dengan maksimal, seperti setiap guru diberikan peluang yang sama untuk menjadi ketua atau panitia inti dalam setiap kegiatan sesuai kurikulum khas Al-Irsyad, serta melakukan control secara proporsional dalam setiap kegiatan akademik dan non-akademik diseluruh unit lembaga sekolah (meliputi jadwal pembelajaran, agenda kegiatan serta ketersediaan pelaksana panitia kegiatan kurikulum khas Al-Irsyad), sehingga guru dapat beraktualisasi diri dalam mencapai kebutuhannya masing-masing (baik untuk melaksanakan kuliah ke jenjang yang lebih tinggi atau aktualisasi lainnya yang positif mendukung pekerjaan). Dengan demikian masing-masing guru dapat mencapai kepuasan kerja dengan aktivitas yang terkontrol (proporsional dan tidak terlalu padat) dampaknya guru tidak akan merasa terbebani dalam pekerjaannya.

\section{SIMPULAN}

Hasildari seluruh uji reliabilitasdanvaliditas menunjukkanseluruhpernyataan dalam setiap variabelvalid dan reliabel. Dalamujiujinormalitas menunjukkan bahwa data memiliki distribusi normal. Berdasarkan hasilpenelitian maka dapat disimpulkan bahwa:

171. 
1. Budaya organisasi, Motivasi kerja, Disiplin kerja dan Kinerja guru Sekolah Islam Terpadu Al-Irsyad Al-Islamiyyah Karawang adalah tinggi.

2. Pengaruh Budaya organisasi terhadap motivasi berpengaruh pada taraf sedang, sedangkan pengaruh budaya organisasi terhadap disiplin kerja dalah kuat.

3. Terdapat hubungan yang rendah antara motivasi dan disiplin.

4. Peran motivasi guru terhadap Kinerja guru sangatlah rendah, tetapi disiplin kerja berperan sangat tinggi dalam meningkatkan kinerjanya.

5. Secara simultan motivasi dan disiplin berpenharuh sangat kuat terhadap peningkatan kinerja.

\section{DAFTAR PUSTAKA}

Barnawi, dan Mohammad Arifin.2012.Kinerja Guru Profesional.Yogyakarta: Ar-Ruzz Media.

Direktorat Jenderal PMPTK (Peningkatan Mutu Pendidik dan Tenaga Kependiaı 2010. Pedoman Pelaksanaan Penilaian Kinerja Guru (PK Guru). Јакаrta :Kementerian Pendidikan Nasional.

Kenneth, N. Wexley, dan Gary, A. Yuki. 2003. Perilaku Organisasi dan Psikologi Personalia. Jakarta : PT RINEKA CIPTA.

Mangkunegara, AA Anwar Prabu. 2013. Manajemen Sumber Daya Manusia Perusahaan. Bandung : PT Remaja Rosda Karya.

Mangkunegara, Anwar Prabu, (2005), Manajemen Sumber Daya Manusia, Bandung Remaja Rosdakarya

Moh. Pabundu Tika, 2014. Budaya Organisasi Dan Peningkatan Kinerja Perusahaan, Jakarta : Bumi Aksara.

Ndraha, Taliziduhu. 2012. Pengantar Teori Pengembangan Sumber Daya Manusia. Jakarta : PT Rineka Cipta.

Raymond, A., Noe., John, R., Hollenbeck., Barry, G. \& Patrick, M.W. (2008). Human Resources Management : Gaining A Competitive Advantage, 6th Edition,McGrawHill/Irwin

Rivai, Veithzal., Sagala J, Ella., 2010. Manajemen Sumber Daya Manusia untuk Perusahaan dari Teori ke Praktik.Jakarta : Raja Grafindo Persada.

Siagian, Sondang P. 2014. Manajemen Sumber Daya Manusia. Jakarta : PT Bumi Aksara.

Sinambela, Lijan Poltak., 2012. Kinerja Guru : Teori Pengukuran dan Implikasi. Yogyakarta : Graha Ilmu.

Tubagus Achmad Darojat, 2015. Konsep-konsep Dasar Manajemen Personalia M Mon Kini. Bandung : PT. Refika Aditama.

Widodo, Suparno Eko. 2015. Manajemen Pengembangan Sumber Daya Manusia. Yogyakarta : Pustaka Pelajar. 